\title{
Powder Diffraction Journal is now Open Access - Hybrid
}

As the publishing world continues to evolve, the International Centre for Diffraction Data $\left(\mathrm{ICDD}^{\circledR}\right)$ is taking steps, along with our publisher, Cambridge University Press, to adapt Powder Diffraction Journal (PDJ) to the needs of both its authors and readers. The proprietor $\left(\mathrm{ICDD}^{\circledR}\right)$ and publisher are also working diligently to meet the needs of Plan S requirements (cOAlition S, 2018), an initiative that requires research funded by public grants to be published in compliant Open Access journals or platforms.

To that end, PDJ is now Open Access - Hybrid. This means both "Green" and "Gold" Open Access options are available to the author. "Green" access allows the author to post final approved manuscripts as a preprint on approved platforms without additional cost. Costs for the final published version of record are still covered by a subscription fee. "Gold" access manuscripts published under the Creative Commons License (Creative Commons, 2002) allows the author to post the final published manuscript without restriction. This option requires article processing charge(s). For the reader, "Green" access allows early view of content on approved platforms but restricts reuse and distribution. "Gold" access allows readers both reuse and distribution privileges, depending on the Creative Commons License used. See Instructions for Contributors (Cambridge University Press, 2019a) for more information. The new License to Publish Agreement (Cambridge University Press, 2019b) is also now available on both the ICDD and Cambridge Core websites.

Agreements with both the University of California (University of California, 2019) and Germany's Max Planck Society (Library Technology Guides, 2019) highlight Cambridge University Press' commitment to and leadership of open research and access. Open research includes both making publications freely available online (open access) and underlying research data (open data). The PDJ staff at ICDD look forward to working with the publisher to continue to transition how it publishes, as well as meet the content needs of its audience.

Should you have any questions or comments, please do not hesitate to contact me. We look forward to publishing content to meet the educational needs of the X-ray Diffraction community.

\section{Nicole Ernst Boris Managing Editor, Powder Diffraction E-mail: boris@icdd.com}

Cambridge University Press (2019a). Powder Diffraction Journal Instructions for Contributors - Cambridge Core. Available at: https://www.cambridge. org/core/journals/powder-diffraction/information/ instructions-contributors (Accessed: 20 August 2019).

Cambridge University Press (2019b). License to Publish - Cambridge Core. Available at: https://www.cambridge.org/core/journals/powder-diffraction/ information/license-to-publish (Accessed: 20 August 2019).

cOAlition S (2018). 'Plan S' and 'cOAlition S' - Accelerating the Transition to Full and Immediate Open Access to Scientific Publications. Available at: https://www.coalition-s.org/ (Accessed: 4 September 2019).

Creative Commons (2002). About The Licenses - Creative Commons. Available at: https://creativecommons.org/licenses/ (Accessed: 4 September 2019).

Library Technology Guides (2019). Cambridge University Press Reaches Major Open Access Agreement With Max Planck Society. Available at: https://librarytechnology.org/pr/24207 (Accessed: 20 August 2019).

University of California Office of Scholarly Communication (2019). Cambridge University Press and the University of California Agree to Open Access Publishing Deal. Available at: https://osc.universityofcalifornia.edu/2019/04/cambridge-uc/ (Accessed: 20 August 2019). 